\title{
ENSINO MÉDIO ARTICULADO AO ENSINO PROFISSIONALIZANTE: NOVAS PERSPECTIVAS
}

\author{
S. L. S. L. M. FREIRE ${ }^{1}$ e N. R. LIMA ${ }^{2}$ \\ 1,2 Mestrado em Educação - Universidade do Estado do Rio Grande do Norte \\ E-mail: silviahpedagogia@gmail.com ${ }^{1}$, nrobertalima@hotmail.com ${ }^{2}$
}

Artigo submetido em março/2012 e aceito em maio/2012

\section{RESUMO}

Neste artigo pretendemos discutir sobre a nova proposta do Ensino Médio articulado ao Ensino profissionalizante, nas instituições SESI e SENAI na cidade de Mossoró/RN. Essa proposta tem por finalidade proporcionar a formação integral, alicerçada nas dimensões do trabalho, ciência e cultura e ampliar as possibilidades de inserção do cidadão na vida produtiva e social, bem como dar continuidade ao seu itinerário formativo, contribuindo para a formação continuada e permanente do aluno. Dessa maneira, objetivamos com esse estudo analisar as contribuições dessa articulação para ensino - aprendizagem do aluno e as possibilidades de construção de novos conhecimentos. O estudo fundamenta-se em documentos como referenciais normativos, pedagógico, operacionais e financeiros nacionais para a articulação da educação básica do SESI com a educação profissional do SENAI (2006), relatório de mapeamento e diagnóstico do Projeto EBEP, Educação básica do SESI articulada com educação Profissional do SENAI (2001; 2011). A ênfase dada pela LDB (Lei de Diretrizes e Bases da Educação) 9.394/96, para a educação profissional deixa claro que deve ser desenvolvida em articulação com o ensino regular ou por diferentes estratégias de educação continuada numa perspectiva do exercício pleno da cidadania. Esta pesquisa é resultado de um trabalho exploratóriobibliográfico que tem como objetivo maior compreender as reflexões e proposições atribuídas a essa articulação médio com o ensino profissionalizante na contemporaneidade.

PALAVRAS-CHAVE: Ensino Médio, Ensino articulado, profissionalizante.

\section{HIGH SCHOOL EDUCATION PROFESSIONAL ARTICLES: NEW PERSPECTIVES}

\section{ABSTRACT}

In this article we intend to discuss the proposed new high school vocational education articulated to, the SESI and SENAI institutions in the city of Mossoró / RN. This proposal aims to provide comprehensive training, based on the dimensions of work, science and culture and expand the possibilities of inclusion of citizens in social and productive life, as well as to continue its process of formation, contributing to the ongoing training and permanent student. Thus, this study aimed to analyze the contributions to this joint education - student learning and the possibilities of constructing new knowledge. The study is based on documents as normative references, educational, financial and operational coordination for the national basic education SESI with Senai Professional Education (2006), mapping report and diagnosis EBEP Project, basic education combined with the SESI Senai Professional education (2001, 2011). The emphasis of the LDB (Law of Guidelines and Bases of Education) 9.394/96, to make it clear that professional education should be developed in conjunction with regular education or different strategies for continuing education in a perspective of full citizenship. This research is a result of exploratory work-literature that aims to understand the biggest reflection and proposals assigned to that joint school with vocational education in contemporary society.

KEY-WORDS: School, Education articulated, professional. 


\section{ENSINO MÉDIO ARTICULADO AO ENSINO PROFISSIONALIZANTE: NOVAS PERSPECTIVAS}

\section{CONTEXTUALIZANDO O PROCESSO HISTÓRICO}

A relação entre educação básica e a educação profissional, no Brasil, sempre foi palco de constantes controvérsias e inversões. Diferentemente da evolução das políticas de oferta da educação básica, a educação profissional ainda não alcançou repercussão nas políticas públicas capazes de garantir ao país a formação de pessoas qualificadas para atenderem ás demandas do setor produtivo.

Para Kuenzer (2001), a história do ensino médio no Brasil é a história do enfrentamento desta tensão, que tem levado não à síntese, mas à polarização fazendo da dualidade estrutural a categoria de análise por excelência, para a compreensão das propostas que vêm se desenvolvendo a partir dos anos 40 .

A industrialização brasileira tardia, ocorrida no final dos anos 1950, foi intensamente prejudicada pela falta de pessoal qualificado e com formação básica capaz de garantir um crescimento sólido do setor industrial brasileiro. Até meados dos anos 1970, a mão de obra da indústria era basicamente formada em serviço, geralmente para funções que requeriam poucos conhecimentos intelectuais e maior habilidade física. (Relatório de Mapeamento e Diagnóstico do Projeto EBEP, 2011)

A década de 70 presenciou uma mudança significativa na política industrial brasileira, com a solidificação da indústria de base e o surgimento de uma indústria de bens de consumo e serviço. Esse período foi marcado pela emergência do modelo educacional embasado na teoria do capital humano, que preconizava a ligação direta entre investimento em educação e crescimento econômico. Esse pensamento teve reflexo direto nas políticas educacionais nos anos subsequentes, mas ainda assim, tais políticas não lograram êxito em responder à necessidade do país na formação de pessoas capacitadas para o pleno exercício da cidadania.

Nas últimas três décadas do século $X X$, a legislação educacional sofreu mudanças significativas no tocante ás relações entre educação básica e educação profissional que refletiu desde a profissionalização compulsória até uma total separação entre as duas modalidades de educação, como se pode observar essa realidade retrata as mudanças na legislação da educação básica e profissional nesse período.

\section{A ARTICULAÇÃO dO ENSINO MÉDIO COM O ENSINO PROFISSIONALIZANTE: NOVAS PERSPECTIVAS}

No sentido etimológico, articular vem do latim articulare, que significa unir, juntar, formando cadeias de relações, vincular-se. Tomando como referência o sentido etimológico do termo, a Ação Articulada da Educação Básica do SESI com a Educação Profissionalizante do SENAI, busca os pontos comuns, cujos processos convergem para os mesmos objetivos. A articulação aqui vista assegura as identidades das instituições envolvidas por meio de uma ação planejada e combinada voltada para a obtenção de finalidades em comuns. 
Assim, o ensino médio no Brasil tem-se constituído ao longo da história da educação brasileira como nível de mais difícil enfrentamento, em termos de sua concepção, estrutura e formas de organização, em decorrência de sua própria natureza de mediação entre educação e a educação profissional.

O novo Ensino Médio agora é para a vida porque a vida necessita de formação geral tanto quanto o mercado de trabalho também exige. Do mesmo jeito, a formação geral exigida pelo mercado é a mesma de que a humanidade precisa para desenvolver suas potencialidades e sua convivência na sociedade (Santos 2007, p.27).

A educação, entendida como referencial de formação permanente e continuada, tem como objetivo o desenvolvimento integral do ser humano, nas suas dimensões ética, social e política, de maneira a preservar a sua dignidade e orientá-lo nas ações perante a sociedade. A educação é dinâmica e histórica, portanto, precisa ler o mundo, marcado por múltiplas transformações. Esse cenário visa à flexibilidade e a contextualização, entendendo o homem como um ser histórico, social e cultural que interage com a natureza e com o outro e, para atender às suas expectativas e necessidades, nessa ação, constrói conhecimento.

O Ensino Médio articulado ao Ensino profissionalizante, nas instituições SESI e SENAI na cidade de Mossoró/RN, tem por finalidade proporcionar a formação integral, alicerçada nas dimensões do trabalho, ciência e cultura e ampliar as possibilidades de inserção do cidadão na vida produtiva e social.

Considerando essa concepção, o SESI e o SENAI devem elaborar sua proposta de ação articulada tendo como foco o aprimoramento da pessoa como uma das finalidades da educação, vista na perspectiva humana, centrada em sujeitos singulares, valorizando-os como cidadãos e como trabalhadores, em suas diversidades e contradições, em uma sociedade em profundas e contínuas transformações.

O projeto EBEP- Educação Básica do SESI, articulada com a Educação Profissional do SENAI é fundamental para oferecer oportunidades educacionais que propiciem a formação integral, alicerçada nas dimensões do trabalho, ciência e cultura, na sua prática e nos seus fundamentos científico-tecnológicos e histórico-sociais, e ampliar as possibilidades de inserção do cidadão na vida produtiva e social bem como dar continuidade ao seu itinerário formativo, contribuindo para a formação continuada e permanente. (Referenciais normativos, pedagógicos, operacionais e financeiros nacionais para a articulação da educação básica do SESI, 2006).

Assim, a perspectiva dessa articulação pressupõe o redimensionamento de conceitos tais como: currículo, trabalho, competências, ensino e aprendizagem, com vistas à efetivação de uma educação emancipatória e empreendedora voltada para a formação da pessoa num processo cultural, na ação humana, no trabalho, no lazer e na convivência com a sociedade.

Nessa ótica, entendemos que a proposta articulada se apresenta como eixo estruturante adequando à contextualização que contribui para a aprendizagem significativa, tornando-se imprescindível, a partir do momento em que viabiliza o ensino com vistas ao desenvolvimento de competências, à valorização de aptidões individuais e à transferência do que foi aprendido, proporcionando aprendizagens com base no universo sociocultural dos alunos, fortalecendo a unidade prática-teórico-prática de vida e de trabalho.

Mediante isso, temos a sociedade do conhecimento e o mundo do trabalho que têm exigido cada vez mais, trabalhadores qualificados, que demonstrem capacidade crítica, que tenham autonomia para gerir seu próprio trabalho, que possuam habilidades para atuarem 
cooperativamente em equipes e que saibam analisar e solucionar criativamente situações desafiadoras, observando os princípios éticos, estéticos e políticos. Nesse sentido a concepção de competência constitui fundamento para a ação articulada.

Não podemos deixar de abordar que no contexto educacional, a compreensão de competência deve ser abrangente e mais fecunda, por considerar a subjetividade e a singularidade dos sujeitos envolvidos nesse cenário, o que significa dizer que a competência é o resultado da mobilização de conhecimentos, habilidades, atitudes e valores de um indivíduo, que se articulam e se transformam continuamente. Essa formação passa a se vista como uma educação emancipatória, a partir do momento em que valoriza cada vez mais no âmbito do trabalho, na convivência das práticas sociais da vida cotidiana, por meio de conhecimentos científicos, tecnológicos e culturais em um movimento de aproximação entre as demandas do mundo do trabalho e da sociedade e as aspirações do cidadão.

\section{A ORGANIZAÇÃO DO CURRICULO NA ARTICULAÇÃO ENSINO MÉDIO E ENSINO PROFISSIONALIZANTE}

O currículo, organização social do conhecimento, deve refletir as intencionalidades vivenciadas e reconstruídas em múltiplos espaços, como ambientes escolares, espaços de trabalho e por múltiplos sujeitos, concebido segundo um processo de seleção, organização, análise e produção de saberes e de visões de mundo, de habilidades, de valores, de símbolos, significados e culturas.

Para tanto, o currículo no âmbito da ação articulada, segundo os Referenciais normativos (2006), é entendido como toda ação pedagógica, será norteado pelos princípios da flexibilidade, interdisciplinaridade, contextualização e pluralismo de idéias e de concepções pedagógicas.

Nessa perspectiva, as escolas do SENAI e do SESI na cidade de Mossoró/RN ao constituírem currículos articulados, alinhados aos seus projetos político-pedagógicos, devem contemplar experiências nas dimensões cognitiva, afetiva, psicomotora, com bases nos valores éticos e referenciais sociais e culturais, levando em conta os contextos local, regional e global, a singularidade de alunos e professores, em consonância com as políticas públicas e com o mundo do trabalho. O processo de articulação dessa maneira constitui oportunidade ímpar para uma sólida formação do cidadão, visando atender as expectativas do mundo do trabalho.

A metodologia diz respeito aos procedimentos teórico-práticos que, alinhados às técnicas são utilizados no processo de ensino e aprendizagem, para facilitar a construção de saberes, habilidades, atitudes e valores necessários ao desenvolvimento das competências. A ação articulada metodológica tem como premissa o fazer participativo, que deve se utilizado em todos os momentos da prática pedagógica por meio de: diálogo de saberes, construção coletiva do conhecimento, aprender fazendo por meio da análise reflexiva da realidade, situações problema, projetos, estudos de caso, vivências, desafios entre outros.

Observamos que a possibilidade prevista na Lei de Diretrizes e Bases da Educação Nacional no 9.394/94 de que o ensino médio possa preparar os estudantes para "o exercício de profissões técnicas", garantida a formação geral (parágrafo segundo do art. 36), é mais uma entre as tantas formas de organização da educação profissional previstas na legislação. 
Esse trabalho passar ser respaldado em consonância com a Lei Diretrizes e Bases da Educação Nacional no 9.394/94 as quais se ratificam os princípios de pluralismo de idéias de concepções pedagógicas que têm como fundamento dois pressupostos básicos: o da autonomia da escola e o da liberdade de opção teórico-metodológica. No entanto a opção metodológica deve ser balizada, segundo os Referenciais normativos (2006), pelos seguintes princípios:

- A contextualização, que reinsere os conhecimentos no âmbito da vida, gerando sentido e significado e transformando definições em conceitos;

- Interdisciplinaridade articula o conhecimento e não dissolve a especificidade dos campos dos saberes. Não nega a disciplina, mais as práticas escolares fragmentadas.

- Flexibilidade, sensibilidade para perceber e adequar os procedimentos a um fazer pedagógico criativo, crítico e adequado à realidade.

A oferta da ação articulada pode ser realizada de forma presencial ou a distância, por meio estratégias regulares e flexível. O SESI e o SENAI assumem que na oferta articulada da ação articulada da educação básica com a educação profissional o planejamento será participativo e levará em consideração o estudo de viabilidade para a definição da oferta dos cursos, bem como dos recursos humanos, didáticos, físicos, tecnológicos e financeiros necessários ao projeto.

O planejamento passa a ser um processo contínuo da ação articulada e deverá de acordo com os Referenciais Normativos (2006):

- Definir objetivos com compromissos coletivos, claramente explicitados em termos de resultados alcançarem, orientando efetivamente a ação;

- Estabelecer os mecanismos de acompanhamento, avaliação e reformulação no processo;

- Atender às demandas do ambiente sem perder a perspectiva da transformação;

- Prever processos de educação continuada para as equipes envolvidas em todos os níveis.

O planejamento deverá levar em consideração os recursos de apoio didático que servirão de suporte para o processo de ensino e aprendizagem, sintonizado com o plano de ação articulada, como: módulos de ensino, livros, materiais audiovisuais, entre outros.

São ações dessa natureza, que traz um grande desafio, tendo em vista a duas realidades ensino médio e ensino profissionalizante, serem distintas, porém essenciais para que ocorra o processo de articulação, além disso, trabalhar as duas grades curriculares e fazer valer, a relação existente nos conteúdos e componentes das mesmas não é tarefa fácil, porém desafiadora, passando a ser o ponto chave desse trabalho articulado.

Para os Referenciais normativos, pedagógicos, operacionais e financeiros nacionais para a articulação básica do SESI com a educação profissional do SENAI (2006, p.27):

\footnotetext{
Os planos de cursos do SESI e do SENAI constituem parte integrante e coerente dos respectivos Projetos Político-Pedagógicos das escolas, e têm por finalidade garantir a organicidade pedagógicas sobre os perfis requeridos em cada etapa e modalidade de formação, os objetivos dos cursos, as organizações curriculares, matrizes de competências(...),em se tratando de educação básica, a matriz de competências constitui referencial para elaboração dos planos de cursos.
}

Outro ponto de suma importância, o qual não pode deixar de ressaltar é o plano de ensino articulado, que seria a efetividade da ação docente, estes são elaborados pelos docentes, concretizando de maneira definitiva e indispensável, a ação educacional articulada. Os planos propiciam o fortalecimento dos nexos entre os elementos interativos da sala de aula, fazendo 
relação entre teoria e prática, são linhas norteadoras que envolvem a organização dos componentes curriculares na ação articulada, devendo retratar as decisões tomados com relação a seus principais elementos constitutivos- competências, conteúdos, metodologias, recursos didáticos e avaliação.

Ao falarmos em planejamento não podemos deixar de contemplar aspectos relacionados a avaliação, tendo em vista a importância da mesma para o processo ensino aprendizagem. A avaliação é vista com uma ação emancipatória e diagnóstica, de forma a dar transparência aos seus objetivos, desempenho e resultados, com a preocupação legítima de garantir a efetividade do sistema.

Dessa maneira, não podemos deixar de abordar os recursos físicos e tecnológicos os quais precisam atender as necessidades da ação articulada, que seriam as instalações físicas e equipar os ambientes de ensino de maneira a atender o público alvo, que possam dá suporte tais como orientados pelo Referencial Normativo (2006):

- Espaços físicos e multimeios;

- Laboratórios/ oficinas, móveis fixos, de forma a permitir a contextualização teoria/prática;

- Compartilhamento de espaços;

- Acervos das bibliotecas entre outros.

Entretanto, percebemos que o espaço físico e as condições de trabalho de certa forma vão favorecer ao planejamento como um todo, tendo em vista que as condições específicas para que favoreça a aplicabilidade do planejamento, precisam está de acordo com o esperado, tendo em vista serem aspectos relevantes ao bom desenvolvimento das atividades pedagógicas.

A formação das turmas, turnos e horários deve ser planejadas conjuntamente, levando-se em consideração a concomitância entre a educação básica e educação profissional, oferecidas ao mesmo aluno, o período das atividades deve contemplar: jornada de trabalho, prática profissional na empresa, horário das aulas, de refeição, deslocamento do aluno entre as unidades e para a realização de atividades pedagógicas, tempo para estudo, entre outros aspectos.

Um aspecto o qual não podemos deixar de elucidar está relacionado ao Estágio Supervisionado e a prática profissional do curso de educação profissional técnica de nível médio, será obrigatório, somente quando constar no plano do curso. Tem como objetivo propiciar aos educandos aprendizado e vivência profissional em situação real de trabalho, possibilitando a percepção efetiva sobre o campo de atuação do técnico, bem como o desenvolvimento de competências em face das exigências do mercado de trabalho. Nesse caso, é recomendado um manual do estágio para regular os procedimentos da realização do mesmo, considerando:

- Legislação e normas;

- Orientações;

- Documentos próprios (Termo de Compromisso, Acordo de Cooperação com empresas, Convênios);

- Plano de atividade do estágio;

- Procedimentos para acompanhamento e avaliação das atividades;

- Disposições do regimento escolar ;

- Seguro obrigatório;

- Outros. 
Segundo os Referenciais normativos, pedagógicos, operacionais e financeiros nacionais para a articulação da educação básica do SESI com a educação profissional do SENAI (2006), é essencial que a estrutura educacional contemple a atividade específica de articulação com a empresa e o acompanhamento do estagiário.

Assim, no âmbito dos cursos de aprendizagem, específicos da formação profissional, quando prevista a sua realização na empresa, deverá ser objeto de plano de desenvolvimento, acompanhamento e avaliação de resultado. O planejamento no que diz respeito ao aspecto curricular deve considerar o tempo necessário à realização do estágio supervisionado quanto a sua prática profissional.

A tabela a baixo exemplifica a matriz curricular do ensino médio e do ensino profissionalizante do curso Técnico em Segurança do Trabalho:

\begin{tabular}{|c|c|c|}
\hline $\begin{array}{l}\text { ENSINO MÉDIO } \\
\text { ÁREAS DE } \\
\text { CONHECIMENTO }\end{array}$ & COMPONENTES CURRICULARES & $\begin{array}{l}\text { EDUCAÇÃO } \\
\text { (TÉCNICO EM SEGURANÇA DO } \\
\text { TRABALHO) }\end{array}$ \\
\hline $\begin{array}{l}\text { Linguagem, Códigos e Suas } \\
\text { Tecnologias }\end{array}$ & $\begin{array}{l}\text { Língua Portuguesa } \\
\text { Língua Estrangeira } \\
\text { Educação Física } \\
\text { Artes } \\
\text { Informática }\end{array}$ & 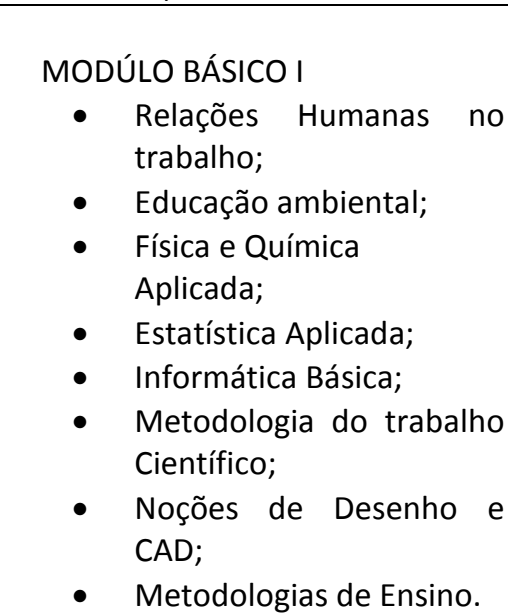 \\
\hline $\begin{array}{l}\text { Ciências Humanas e suas } \\
\text { Tecnologias }\end{array}$ & $\begin{array}{l}\text { Sociologia } \\
\text { Filosofia } \\
\text { História } \\
\text { Geografia }\end{array}$ & 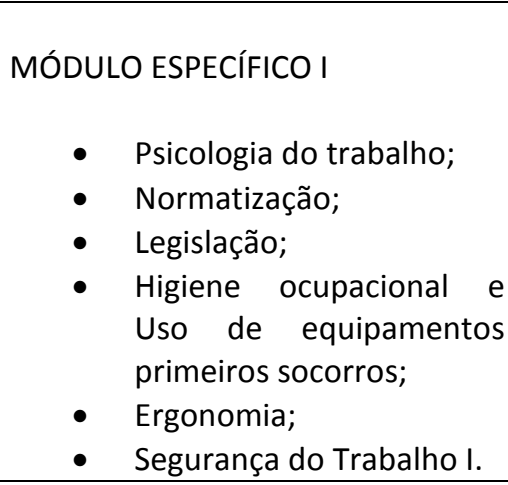 \\
\hline $\begin{array}{l}\text { Ciências da Natureza, Matemática } \\
\text { e Suas Tecnologias }\end{array}$ & $\begin{array}{l}\text { Biologia } \\
\text { Química } \\
\text { Física } \\
\text { Matemática }\end{array}$ & $\begin{array}{l}\text { MÓDULO ESPECÍFICO II } \\
\text { - Segurança do Trabalho II; } \\
\text { - Política de saúde e } \\
\text { - } \text { segurança do trabalho; } \\
\text { Prevenção e controle de } \\
\text { perdas epidemiologia, } \\
\text { Toxicologia e doenças } \\
\text { profissionais } \\
\text { prevenção/Combate a } \\
\text { Sinistro } \\
\text { MÓDULO DE GESTÃO }\end{array}$ \\
\hline
\end{tabular}

Fonte: Referenciais normativos SESI (2006) 


\section{FORMAÇÃO E DESENVOLVIMENTO DAS EQUIPES ARTICULADAS}

O projeto Educação Básica e Educação Profissional - EBEP constitui uma proposta de formação da cidadania. A formação e o desenvolvimento das equipes articuladas fundamenta- se na experiência, nos referenciais teóricos e no contexto social.

O desenvolvimento profissional das equipes atuantes requer fundamentos pedagógicos e competências adequadas aos objetivos do projeto. Constituir esses fundamentos e desenvolver essas competências exigem a elaboração de um Plano de Desenvolvimento para as equipes articuladas, constituído dos seguintes elementos: Objetivos, competências, estratégias metodológicas, recursos financeiros, cronograma de curto e médio prazos e resultados e impactos esperados. Segundo os Referenciais normativos, pedagógicos, operacionais e financeiros nacionais para a articulação da educação básica do SESI com a educação profissional do SENAI (2006).

Dessa forma, serão necessárias as unidades escolares SESI e do SENAI manterem seus respectivos registros organizados, em separado, segundo os padrões exigidos pelas Secretarias, Conselhos Estaduais e os Regimentos Escolares.

\section{OS DESAFIOS DA AÇÃO ARTICULADA: ENSINO MÉDIO E ENSINO PROFISSIONALIZANTE}

O trabalho, como ação humana, é o resultado da produção do homem, constituindo instrumentos de sobrevivência. A experiência do trabalho significa criar e aprender como parte integrante do cotidiano dos cidadãos, no local de trabalho e de ensino em seus vários níveis e modalidades. (Referenciais Normativos, Pedagógicos, Operacionais e Financeiros Nacionais Para a Articulação 2006, p. 20).

Mediante a isso, educação exprime, com efeito, elementos diferenciados, mas recorrente de construção e acumulação de conhecimentos teórico-práticos necessários ao indivíduo no seu relacionamento com a natureza, conforme seus interesses e necessidades e, portanto, indispensáveis à formação.

Assim, os profissionais envolvidos docentes, técnicos e pessoais de apoio- na oferta da ação articulada devem ser definidos e nominados, com as respectivas responsabilidades, precisam responsabilizar-se em fundamenta-se na experiência, nos referenciais teóricos e no contexto social, além disso, o desenvolvimento profissional dessas equipes atuantes requer também fundamentos pedagógicos adequados aos objetivos da ação articulada, tendo em vista que as competências requeridas deverão ser feita com os envolvidos, para atender às reais necessidades e expectativas do trabalho articulado.

Com isso fica a mercê do inacabado o grande desafio que é trabalhar com essa articulação, tendo em vista articular conteúdos do ensino médio com os conteúdos do ensino profissionalizante, requer uma demanda de tempo, disponibilidade, além disso, fazer com que os alunos e profissionais da educação possam dá sentido a essa junção de conhecimento. Por entendermos que ensinar no processo interativo requer uma relação dialógica que se concretiza no contato do homem como o mundo vivenciado, a partir do momento em que estabelece trocas em suas múltiplas formas relacionais. 


\section{REFERÊNCIAS BIBLIOGRÁFICAS}

1. Referenciais normativos, pedagógico, operacionais e financeiros nacionais para a articulação da educação básica do SESI com a educação profissional do SENAI. Brasília: SESI/DN; SENAI/DN, 2006.

2. Serviço Nacional de Aprendizagem Industrial. Departamento Nacional Educação Básica SESI, educação profissional SENAI: relatório de mapeamento e diagnóstico do Projeto EBEP, Educação básica do SESI Articulada com educação Profissional do SENAI. Brasília, 2011.

3. SANTOS, Jean Mac Cole Tavares. De Novo Ensino Médio aos problemas de sempre: entre marasmos, apropriações e resistências escolares. Fortaleza: Edições UFC, 2007.

4. KUENZER, Acacia. Ensino Médio e Profissional: as políticas do Estado neoliberal. 3ạ ed.São Paulo: Cortez, 2001 